\title{
Polymorphisms of PTPN11 gene could influence serum lipid levels in a sex-specific pattern
}

\author{
Zhi-Fang Jia ${ }^{1}$, Xue-Yuan Cao ${ }^{2}$, Dong-Hui Cao ${ }^{1}$, Fei Kong ${ }^{1}$, Punyaram Kharbuja ${ }^{2}$ and Jing Jiang ${ }^{1 *}$
}

\begin{abstract}
Background: Previous studies have reported that different genotypes of PTPN11 gene (protein tyrosine phosphatase, non-receptor 11) were associated with different levels of serum lipids. The aim of this study was to explore the relationship between single nucleotide polymorphisms (SNPs) of PTPN11 and serum lipids in Northeast Chinese.

Methods: A total of 1003 subjects, 584 males and 419 females, were included in the study and their serum lipids were determined. Five htSNPs (rs2301756, rs12423190, rs12229892, rs7958372 and rs4767860) of PTPN11 gene were genotyped using TaqMan assay method.

Results: All of the five SNPs were in Hardy-Weinberg equilibrium. The male subjects had higher triglyceride (TG), higher low-density lipoprotein cholesterol (LDL-C) and lower high-density lipoprotein cholesterol (HDL-C) level than females. In males, rs4767860 was found to be associated with serum TG and total cholesterol (TC) levels and rs12229892 was associated with TC level. However, these significant associations could not be observed in females. In females, rs2301756 was found to be associated with TG and rs7958372 was associated with LDL-C level. Haplotype analysis showed that the GCGTG haplotype was associated with slightly higher TG level and ATGCG with higher TC level.
\end{abstract}

Conclusions: SNPS of PTPN11 may play a role in serum lipids in a sex-specific pattern. However, more studies are needed to confirm the conclusion and explore the underlying mechanism.

Keywords: PTPN11, Single nucleotide polymorphism (SNP), Triglyceride (TG), Total cholesterol (TC), Low-density lipoprotein cholesterol (LDL-C), High-density lipoprotein cholesterol (HDL-C)

\section{Introduction}

Dyslipidemia such as the increased levels of total cholesterol (TC), triglyceride (TG) or the decreased level of high-density lipoprotein cholesterol (HDL-C) has been concluded to be involved in the higher risk of cardiaccerebral vascular disease [1-3] and has become a serious public health problem [4]. It is a complex trait that many factors, environmental and genetic [5,6], have been reported to be associated with it. However, these factors could only explain part of the total variance, and more factors need to be identified.

Src homology-2 domain-containing protein tyrosine phosphatase 2 (SHP2), a ubiquitously expressed protein tyrosine phosphatase, plays an essential role in many cell

\footnotetext{
* Correspondence: jiangjing19702000@jlu.edu.cn

${ }^{1}$ Division of Clinical Epidemiology, First Hospital of Jilin University,

Changchun 130021, China

Full list of author information is available at the end of the article
}

signaling events such as metabolic control and transcription regulation $[7,8]$. SHP2 could regulate the apoB (apolipoprotein B) secretion in insulin-dependent pattern via phosphatidylinositol $3^{\prime}$-kinase $[9,10]$. SHP2 activity was associated with the expression of the fatty acid-metabolizing enzyme Acyl-CoA synthetase 4 (ACSL4) [11] and the synthesis of steroid [12]. SHP2 deletion mice could develop a profile of higher serum levels of cholesterol, TG, and low-density lipoprotein [8]. Single nucleotide polymorphisms (SNPs) of protein tyrosine phosphatase, non-receptor 11 (PTPN11) gene, which encodes SHP2, may be associated with serum lipid levels via changing the activity of SHP2 on lipometabolism.

Jamshidi et al. first reported that one of the tagging SNPs of the PTPN11 gene, rs11066320, was associated with serum low-density lipoprotein cholesterol (LDL-C) level in normal Caucasian female twins [13] and Lu et al.
C Biomed Central

(c) 2013 Jia et al.; licensee BioMed Central Ltd. This is an Open Access article distributed under the terms of the Creative Commons Attribution License (http://creativecommons.org/licenses/by/2.0), which permits unrestricted use, distribution, and reproduction in any medium, provided the original work is properly cited. 
reported that rs11066322 was associated with plasma HDL-C level. The data from Hapmap database show that variants of PTPN11 gene present great varieties in different ethnicities. The role of PTPN11 gene on lipid profile has not been described in Chinese so far. The aim of this study was to explore the association of tagging SNPs of PTPN11 gene and lipid levels in Chinese normal people.

\section{Methods \\ Subjects}

From January to December 2009, people who attended the physical examination center of the First Hospital of Jilin University were invited to the study. A total of 1080 persons signed the informed consent and agreed to participate in this study. Subjects who had been taking lipid-lowing medication were excluded from the analysis $(n=73)$. At last, 1003 subjects, 584 males and 419 females, were included in the analysis. The range of age was from 35 to 79 years, with a median of 49 years. This study protocol was approved by the ethics committee of the First Hospital of Jilin University.

Venous blood samples were obtained from all subjects after overnight fasting. The levels of serum TC, TG, HDL-C and LDL-C were determined by enzymatic methods in an autoanalyzer (Type 7600; Hitachi Ltd., Japan) in our Clinical Laboratory Center. The inter-day coefficient variations (CV) of the two distinct analyte levels (Bio-Rad, USA) of the lab were $3.17 \%$ and $3.90 \%$ for TC, $2.74 \%$ and $2.64 \%$ for TG, $3.85 \%$ and $4.08 \%$ for HDL-C, $3.72 \%$ and $3.37 \%$ for LDL-C during the researching period.

\section{Tagging SNPs selection and genotyping}

SNP tagging was to identify a set of SNPs that efficiently tags all known SNPs. Haplotype tagging SNPs (htSNPs) were selected from the Han Chinese data in the HapMap Project (06-02-2009 HapMap) using the SNPbrowser ${ }^{\text {TM }}$ Software v4.0 to capture SNPs with a minimum minor allele frequency (MAF) of 0.05 with a pair-wise $r$ square of 0.8 or greater [14]. There were nine SNPs at MAF $>0.05$ in the PTPN11 gene in Chinese on HapMap, all of which were located in non-coding regions. Five SNPs, rs2301756, rs12423190, rs12229892, rs7958372 and rs4767860, were selected as htSNPs for further study.

Genomic DNA was extracted from whole blood following the protocols provided by the manufacturer (Axygen, USA). Genotypes of each SNP were determined using TaqMan SNP genotying assays (Applied Biosystems, USA) and the detailed process of polymerase chain reaction (PCR) was described elsewhere [15]. The amplified products of PCR were read on ABI PRISM 7900 Sequence Detector in the end-point mode and genotypes were identified using the Allelic Discrimination Sequence Detector Software V2.3.

\section{Statistical analysis}

Categorical data were described as frequency and percentage and compared using $\chi^{2}$ test or Fisher exact test when appropriate. Continuous variables were summarized as median (25th to 75th percentiles) and compared by Kraskal-Wallis test among groups. The frequencies of genotypes of each SNP were determined via direct counting and deviation from Hardy-Weinberg equilibrium was assessed by a goodness-of-fit $\chi^{2}$ test. Levels of TC, TG, HDL-C and LDL-C were transformed to their logarithms to improve the normality of distribution. Associations of the SNPs and lipid levels were assessed using analysis of covariance within each gender type, adjusted for age, body mass index (BMI) and waist circumference. The above analyses were performed in SAS 9.1.3 software (SAS Institute Inc, USA). For haplotypes with frequencies $>1 \%$, their associations with lipids were assessed compared to the most common haplotype using the linear regression model with the HAPSTAT software 3.0 [16]. The statistical significance was $P<0.05$.

\section{Results}

The baseline characteristics of the subjects are shown in Table 1 . The body mass index (BMI) was higher than $24.0 \mathrm{Kg} / \mathrm{m}^{2}$ in half of the subjects (the median value of BMI was $24.0 \mathrm{Kg} / \mathrm{m}^{2}$, with a quartile range from 21.9 to $26.1 \mathrm{Kg} / \mathrm{m}^{2}$ ). No difference was observed between males and females in terms of age, but BMI and waist circumference were higher in males than in females.

The linkage disequilibrium structure of the five SNPs studied, rs2301756, rs12423190, rs12229892, rs7958372 and rs4767860 is presented in Table 2. They were all in linkage disequilibrium, though to different extents. All of the five SNPs were in Hardy-Weinberg equilibrium ( $P=0.540,0.354,0.778,0.858,0.489$, respectively). There were no significant differences in the distribution of genotypes between males and females (Table 1). And no differences were observed among genotypes of each SNP in terms of age, sex, BMI and waist circumference (data were not shown).

As lipid levels of males were different from those of females, except for cholesterol (Table 1), separate analyses were performed on the association of lipid levels and SNPs.

In males, the median serum level of TG was $1.61 \mathrm{mmol} /$ $\mathrm{L}$, with a quartile range $1.16-2.44 \mathrm{mmol} / \mathrm{L}$. Rs4767860 and rs12229892 were observed to be associated with TG level after controlling for the effects of age, waist circumference and BMI in male subjects. The genotype GG or GA of rs4767860 was found to be with higher TG level compared to the most common genotype AA $(P=0.028$, 0.024 , respectively), and genotype AA of rs12229892 was associated with lower TG level compared to genotype GG $(P=0.009$, Table 3$)$. The median level of TC was $5.03 \mathrm{mmol} / \mathrm{L}$, and subjects bearing GG genotype of 
Table 1 Characteristics of subjects included

\begin{tabular}{|c|c|c|c|c|}
\hline & All $(n=1003)$ & Male $(n=584)$ & Female $(n=419)$ & $P$ \\
\hline Age (year) & $49(45-55)$ & $49(45-54)$ & $48(44-56)$ & 0.640 \\
\hline Waist (cm) & 85 (77-92) & 90 (84-94) & 77 (72-83) & $<0.001$ \\
\hline BMI $\left(\mathrm{Kg} / \mathrm{m}^{2}\right)$ & $24.0(21.9-26.2)$ & $24.9(23.0-26.7)$ & $22.6(20.7-24.9)$ & $<0.001$ \\
\hline TG (mmol/L) & $1.44(0.98-2.12)$ & $1.61(1.16-2.44)$ & $1.21(0.84-1.73)$ & $<0.001$ \\
\hline TC $(\mathrm{mmol} / \mathrm{L})$ & $5.04(4.49-5.66)$ & $5.03(4.48-5.68)$ & $5.09(4.52-5.64)$ & 0.669 \\
\hline HDL-C (mmol/L) & $1.33(1.15-1.56)$ & $1.27(1.10-1.45)$ & $1.48(1.27-1.70)$ & $<0.001$ \\
\hline LDL $-C(m m o l / L)$ & $3.09(2.63-3.60)$ & $3.10(2.69-3.63)$ & $3.00(2.53-3.54)$ & $<0.001$ \\
\hline \multicolumn{5}{|l|}{ rs2301756 } \\
\hline GG & $750(74.8 \%)$ & 439 (75.2\%) & $311(74.2 \%)$ & \multirow[t]{3}{*}{0.625} \\
\hline GA & 232 (23.1\%) & $131(22.4 \%)$ & $101(24.1 \%)$ & \\
\hline AA & $21(2.1 \%)$ & $14(2.4 \%)$ & $7(1.7 \%)$ & \\
\hline \multicolumn{5}{|l|}{ rs12423190 } \\
\hline$\pi$ & $515(51.3 \%)$ & $304(52.0 \%)$ & $211(50.4 \%)$ & \multirow[t]{3}{*}{0.782} \\
\hline $\mathrm{TC}$ & 399 (39.8\%) & 227 (38.9\%) & $172(41.0 \%)$ & \\
\hline $\mathrm{CC}$ & 89 (8.9\%) & 53 (9.1\%) & $36(8.6 \%)$ & \\
\hline \multicolumn{5}{|l|}{ rs12229892 } \\
\hline GG & $342(34.1 \%)$ & $189(32.4 \%)$ & $153(36.5 \%)$ & \multirow[t]{3}{*}{0.271} \\
\hline GA & 485 (48.4\%) & $285(48.8 \%)$ & $200(47.7 \%)$ & \\
\hline $\mathrm{AA}$ & $176(17.5 \%)$ & $110(18.8 \%)$ & 66 (15.8\%) & \\
\hline \multicolumn{5}{|l|}{ rs7958372 } \\
\hline$\pi$ & 751 (74.9\%) & $439(75.2 \%)$ & $312(74.5 \%)$ & \multirow[t]{3}{*}{0.962} \\
\hline $\mathrm{TC}$ & 235 (23.4\%) & 135 (23.1\%) & $100(23.9 \%)$ & \\
\hline $\mathrm{CC}$ & 17 (1.7\%) & $10(1.7 \%)$ & $7(1.7 \%)$ & \\
\hline \multicolumn{5}{|l|}{ rs4767860 } \\
\hline AA & 335 (33.4\%) & 198 (33.9\%) & $137(32.7 \%)$ & \multirow[t]{3}{*}{0.666} \\
\hline $\mathrm{GA}$ & 480 (47.9\%) & $282(48.3 \%)$ & $198(47.3 \%)$ & \\
\hline GG & 188 (18.7\%) & $104(17.8 \%)$ & $84(20.0 \%)$ & \\
\hline
\end{tabular}

Unless indicated, data were described as median (Q1-Q3).

rs4767860, were found to have slightly higher serum TC compared to subjects with genotype AA (5.13 v.s. $4.98 \mathrm{mmol} / \mathrm{L}, P=0.021)$ in males. The median levels of HDL-C and LDL-C were $1.27 \mathrm{mmol} / \mathrm{L}$ and $3.10 \mathrm{mmol} / \mathrm{L}$, respectively, and no SNP was found to be related to them.

In females, however, the results were different. Female subjects had lower TG (1.21 v.s. $1.61 \mathrm{mmol} / \mathrm{l})$, lower LDL-C (3.00 v.s. $3.10 \mathrm{mmol} / \mathrm{L})$ and higher HDL-C (1.48 v.s. $1.27 \mathrm{mmol} / \mathrm{L}$ ) level than males. The SNPs which were found to be significantly associated with TC or TG level in males could not be repeated in females. However, two other SNPs, rs2301756 and rs7958372, were found to be significantly associated with lipid level in females. The AA genotype of $\operatorname{rs} 2301756(P=0.005)$ was found to be associated with higher serum TG level and the CC genotype of rs7958372 $(P=0.019)$ was associated with higher LDL-C

Table 2 The linkage disequilibrium coefficient (Lewontin'sD' and $\mathbf{r}^{2}$ ) between SNPs of PTPN11

\begin{tabular}{lccccc}
\hline & rs2301756 & rs12423190 & rs12229892 & rs7958372 & rs4767860 \\
\hline rs2301756 & - & 0.038 & 0.103 & 0.871 & 0.194 \\
rs12423190 & 0.774 & - & 0.289 & 0.055 & 0.509 \\
rs12229892 & 0.953 & 1.000 & - & 0.107 & 0.512 \\
rs7958372 & 0.944 & 0.937 & 0.984 & - & 0.201 \\
rs4767860 & 0.956 & 0.968 & 0.980 & 0.982 & - \\
\hline
\end{tabular}

Values on the left of "-" were Lewontin's D' coefficients and on the right were $r^{2}$. 
Table 3 Associations between SNPs of PTNP11 and lipid levels stratified by gender

\begin{tabular}{|c|c|c|c|c|c|c|c|c|c|}
\hline \multirow{2}{*}{\multicolumn{2}{|c|}{$\begin{array}{c}\text { Frequency } \\
(\%)\end{array}$}} & \multicolumn{2}{|l|}{ TG } & \multicolumn{2}{|l|}{$\mathrm{TC}$} & \multicolumn{2}{|l|}{ HDL-C } & \multicolumn{2}{|l|}{ LDL-C } \\
\hline & & Median (Q1-Q3) & $P$ & Median (Q1-Q3) & $P$ & Median (Q1-Q3) & $P$ & Median (Q1-Q3) & $P$ \\
\hline \multicolumn{10}{|c|}{ Male $(n=584)$} \\
\hline \multicolumn{10}{|c|}{ rs2301756 } \\
\hline GG & $439(75.2)$ & $1.59(1.09-2.37)$ & - & $5.02(4.45-5.63)$ & - & $1.25(1.10-1.43)$ & - & $3.10(2.68-3.61)$ & - \\
\hline GA & $131(22.4)$ & $1.63(1.20-2.47)$ & 0.319 & $5.07(4.52-5.84)$ & 0.161 & $1.30(1.10-1.47)$ & 0.164 & $3.10(2.68-3.74)$ & 0.236 \\
\hline AA & $14(2.4)$ & $1.74(1.19-2.85)$ & 0.516 & $5.03(4.76-5.32)$ & 0.877 & $1.30(1.12-1.60)$ & 0.572 & $2.98(2.75-3.65)$ & 0.969 \\
\hline \multicolumn{10}{|c|}{ rs12423190 } \\
\hline$\pi$ & $304(52.0)$ & $1.57(1.08-2.44)$ & - & $4.99(4.46-5.57)$ & - & $1.27(1.10-1.47)$ & - & $3.10(2.65-3.62)$ & - \\
\hline TC & $227(38.9)$ & $1.67(1.26-2.33)$ & 0.184 & $5.10(4.49-5.74)$ & 0.411 & $1.26(1.09-1.42)$ & 0.309 & $3.14(2.70-3.63)$ & 0.380 \\
\hline CC & $53(9.1)$ & $1.64(1.08-2.68)$ & 0.120 & $5.07(4.49-5.76)$ & 0.219 & $1.30(1.07-1.51)$ & 0.203 & $3.00(2.72-3.70)$ & 0.595 \\
\hline \multicolumn{10}{|c|}{ rs12229892 } \\
\hline GG & $189(32.4)$ & $1.67(1.21-2.53)$ & - & $5.13(4.53-5.72)$ & - & $1.30(1.10-1.47)$ & - & $3.11(2.70-3.67)$ & - \\
\hline GA & $285(48.8)$ & $1.61(1.20-2.45)$ & 0.405 & $5.02(4.49-5.64)$ & 0.106 & $1.23(1.10-1.41)$ & 0.988 & $3.14(2.67-3.66)$ & 0.386 \\
\hline AA & 110 (18.8) & $1.41(0.96-2.16)$ & 0.009 & $4.96(4.35-5.50)$ & 0.118 & $1.29(1.14-1.49)$ & 0.562 & $3.08(2.64-3.57)$ & 0.354 \\
\hline \multicolumn{10}{|c|}{ rs7958372 } \\
\hline$\pi$ & $439(75.2)$ & $1.59(1.10-2.37)$ & - & $5.03(4.46-5.64)$ & - & $1.25(1.10-1.43)$ & - & $3.10(2.69-3.61)$ & - \\
\hline TC & $135(23.1)$ & $1.64(1.20-2.47)$ & 0.351 & $5.05(4.54-5.77)$ & 0.200 & $1.30(1.10-1.47)$ & 0.197 & $3.10(2.68-3.74)$ & 0.260 \\
\hline CC & $10(1.7)$ & $1.89(1.22-2.85)$ & 0.619 & $4.86(4.56-5.28)$ & 0.648 & $1.30(1.12-1.45)$ & 0.615 & $2.94(2.61-3.65)$ & 0.535 \\
\hline \multicolumn{10}{|c|}{ rs4767860 } \\
\hline AA & 198 (33.9) & $1.53(1.02-2.37)$ & - & $4.98(4.42-5.51)$ & - & $1.25(1.10-1.45)$ & - & $3.10(2.60-3.60)$ & - \\
\hline GA & $282(48.3)$ & $1.63(1.20-2.41)$ & 0.024 & $5.03(4.48-5.68)$ & 0.185 & $1.28(1.09-1.43)$ & 0.973 & $3.10(2.67-3.60)$ & 0.252 \\
\hline GG & $104(17.8)$ & $1.64(1.22-2.64)$ & 0.028 & $5.13(4.56-5.80)$ & 0.021 & $1.30(1.10-1.47)$ & 0.598 & $3.15(2.75-3.71)$ & 0.084 \\
\hline \multicolumn{10}{|c|}{ Female $(n=419)$} \\
\hline \multicolumn{10}{|c|}{ rs2301756 } \\
\hline GG & $311(74.2)$ & $1.19(0.83-1.71)$ & - & $4.94(4.49-5.60)$ & - & $1.48(1.27-1.69)$ & - & $2.98(2.50-3.43)$ & - \\
\hline GA & $101(24.1)$ & $1.25(0.85-1.85)$ & 0.780 & $5.23(4.72-5.87)$ & 0.071 & $1.51(1.27-1.76)$ & 0.283 & $3.12(2.66-3.69)$ & 0.083 \\
\hline AA & $7(1.7)$ & $2.33(1.14-3.20)$ & 0.005 & $5.02(4.53-6.20)$ & 0.300 & $1.37(1.21-1.59)$ & 0.605 & $3.16(2.42-3.84)$ & 0.555 \\
\hline \multicolumn{10}{|c|}{ rs12423190 } \\
\hline$\pi$ & $211(50.4)$ & $1.25(0.82-1.75)$ & - & $5.03(4.53-5.67)$ & - & $1.50(1.27-1.71)$ & - & $3.04(2.57-3.56)$ & - \\
\hline TC & $172(41.0)$ & $1.18(0.87-1.64)$ & 0.592 & $5.12(4.47-5.68)$ & 0.709 & $1.46(1.26-1.66)$ & 0.149 & $3.00(2.47-3.56)$ & 0.759 \\
\hline CC & $36(8.6)$ & $1.10(0.80-1.99)$ & 0.388 & $5.00(4.64-5.32)$ & 0.877 & $1.40(1.22-1.74)$ & 0.184 & $2.97(2.52-3.35)$ & 0.895 \\
\hline \multicolumn{10}{|c|}{ rs12229892 } \\
\hline GG & $153(36.5)$ & $1.21(0.85-1.71)$ & - & $5.11(4.57-5.64)$ & - & $1.48(1.26-1.70)$ & - & $3.00(2.65-3.48)$ & - \\
\hline GA & $200(47.7)$ & $1.23(0.86-1.74)$ & 0.497 & $5.04(4.45-5.67)$ & 0.599 & $1.45(1.27-1.68)$ & 0.880 & $3.00(2.51-3.60)$ & 0.873 \\
\hline AA & $66(15.8)$ & $1.19(0.80-1.68)$ & 0.232 & $5.07(4.60-5.61)$ & 0.463 & $1.53(1.30-1.77)$ & 0.128 & $3.07(2.67-3.40)$ & 0.526 \\
\hline \multicolumn{10}{|c|}{ rs7958372 } \\
\hline$\pi$ & $312(74.5)$ & $1.19(0.83-1.71)$ & - & $4.95(4.50-5.60)$ & - & $1.48(1.27-1.69)$ & - & $2.98(2.51-3.44)$ & - \\
\hline TC & $100(23.9)$ & $1.25(0.87-1.88)$ & 0.787 & $5.22(4.67-5.93)$ & 0.090 & $1.52(1.26-1.76)$ & 0.319 & $3.10(2.62-3.63)$ & 0.278 \\
\hline CC & $7(1.7)$ & $1.92(0.85-2.33)$ & 0.201 & $5.02(4.68-6.20)$ & 0.183 & $1.31(1.21-1.59)$ & 0.418 & $3.48(3.16-4.06)$ & 0.019 \\
\hline \multicolumn{10}{|c|}{ rs4767861 } \\
\hline AA & $137(32.7)$ & $1.23(0.81-1.68)$ & - & $4.94(4.53-5.61)$ & - & $1.51(1.30-1.70)$ & - & $3.00(2.57-3.40)$ & - \\
\hline GA & $198(47.3)$ & $1.21(0.86-1.79)$ & 0.474 & $5.11(4.45-5.64)$ & 0.515 & $1.45(1.24-1.70)$ & 0.113 & $2.96(2.46-3.54)$ & 0.600 \\
\hline GG & $84(20.0)$ & $1.21(0.84-1.91)$ & 0.134 & $5.16(4.68-5.87)$ & 0.123 & $1.41(1.26-1.67)$ & 0.236 & $3.13(2.68-3.58)$ & 0.132 \\
\hline
\end{tabular}


level when compared to their most common genotype (Table 3). None of the five SNPs was observed to be associated with TC or HDL-C level.

Because of the linkage disequilibrium, 18 haplotypes were observed using HAPSTAT software which estimated haplotype frequencies based on an EM algorithm and only four of them had the frequencies greater than $1 \%$ (Table 4). The GCGTG haplotype, with an estimated frequency of $27.75 \%$, was found to be significantly associated with the increased level of serum TG compared to the most common haplotype GTATA (41.17\%) after adjusting for age, sex, BMI and waist circumference (The slope of the linear regression is $0.054, P=0.042$ ). The ATGCG haplotype (12.71\%) was found to be associated with slightly higher TC level (The slope of the linear regression is 0.027 , $P=0.030)$. None of the haplotypes was found to be associated with HDL-C or LDL-C.

\section{Discussion}

The results of our study showed that lipid profile was different between males and females that the serum TG and LDL-C levels were higher and HDL-C lower in males than in females. But no difference was observed in the level of TC. These results were similar to those of previous reports $[17,18]$.

The associations between SNPs of PTPN11 gene and serum lipid levels in 1003 Chinese people presented a sex-specific pattern though the distribution of genotypes had no differences between the two sexes. Rs4767860 and rs12229892 were associated with TG level in males, but these significant associations could not be observed in females. In females, the genotype AA of rs 2301756 was found to be associated with higher TG compared to the most common genotype GG. The SNP of rs4767860 was associated with TC in males but no SNP was related to TC in females.

Genotypes of SNPs of PTPN11 varied in different ethnicities. In our study, the genotypes of GG, GA and AA of rs 2301756 were $75.2 \%, 22.4 \%$ and $2.4 \%$, respectively. They were similar to those of Japanese $(62.1 \%, 32.9 \%$ and $5.0 \%$, respectively) [19] but absolutely different from those of Caucasian $(0.5 \%, 13.2 \%$ and $86.3 \%$, respectively) [13]. The data from Hapmap show that rs12229892 and rs4767860 are very rare or do not exist in Caucasian and African Americans while in Chinese and Japanese these two SNPs are very common. The A allele of rs 12229892 was $41.7 \%$ and $\mathrm{G}$ allele of rs 4767860 was $42.7 \%$ in our study. The $\mathrm{C}$ allele of rs7958372 in HapMap database is the dominant allele in Caucasian while in Asian it is the minor allele (13.4\% in our study). Considering the diversity of variants of PTPN11 in different ethnicities, the positive associations observed in our study might not be repeated in other ethnic populations.

The PTPN11 gene, which encodes SHP2, has been reported to be associated with helicobacter pylori-related gastric atrophy $[15,20]$ and gastric cancer [21]. Jamshidi et al. [13] first selected three htSNPs of PTPN11 gene (rs2301756, rs11066320 and rs11066322) and assessed their associations with serum lipid levels in a Caucasian female population. They found that subjects with AA genotype of rs11066320 had lower LDL-C by $2.6 \%$ compared to subjects with GG genotype. They also observed a non-significant increasing trend of TG level from $1.26 \mathrm{mmol} / \mathrm{L}$ in rs11066322 GG genotype carriers to $1.47 \mathrm{mmol} / \mathrm{L}$ of AA genotype carriers. Lu et al. [22] reported that genotype AA of rs11066322 of PTPN11 was associated with the higher plasma HDL-C levels. However, the htSNPs were different in Chinese population. One of the SNPs, rs11066320, which had MAF $>0.05$ in Caucasian, did not exist in Chinese and Japanese [19]. Rs2301756 and rs11066322 were in complete disequilibrium that rs11066322 could not be chosen as htSNP. Okada et al. [19] reported that the HDL-C levels were different in the non-smokers and the current smokers within the same rs2301756 genotype, however, the role of rs2301756 was not assessed. In our study, rs2301756 was associated with TG level in females that subjects of AA genotype had higher TG than subjects of GG genotype. The mechanism underlying these associations was still in the stage of hypothesis which stated that the SNPs of PTPN11 might change the expression of the gene and consequently influenced the protein encoded, SHP2, which could regulate lipometabolism $[9,10]$.

Two limitations should be noted in our study. The first one was only htSNPs with MAF $>5 \%$ were studied. We could not rule out the possibility that other SNPs,

Table 4 Haplotype analysis of SNPs of PTPN11 on the lipid levels

\begin{tabular}{|c|c|c|c|c|c|c|c|c|c|}
\hline \multirow[t]{2}{*}{ Haplotype } & \multirow[t]{2}{*}{ Frequency } & \multicolumn{2}{|c|}{ TG } & \multicolumn{2}{|c|}{$\mathrm{TC}$} & \multicolumn{2}{|c|}{ HDL-C } & \multicolumn{2}{|c|}{ LDL-C } \\
\hline & & b & $P$ & b & $P$ & b & $P$ & b & $P$ \\
\hline GTATA & $41.17 \%$ & Reference & - & Reference & - & Reference & - & Reference & - \\
\hline GCGTG & $27.75 \%$ & 0.054 & 0.042 & 0.013 & 0.157 & -0.018 & 0.099 & 0.006 & 0.624 \\
\hline GTGTA & $15.26 \%$ & 0.028 & 0.389 & -0.006 & 0.619 & -0.002 & 0.841 & -0.017 & 0.265 \\
\hline ATGCG & $12.71 \%$ & 0.050 & 0.165 & 0.027 & 0.030 & 0.014 & 0.343 & 0.028 & 0.082 \\
\hline
\end{tabular}

Differences between haplotype groups were assessed using the linear regression model adjusted for age, sex, BMI and waist circumference. $P$ value in bold indicated the difference was significant comparing to the most common haplotype group $(P<0.05)$.

SNPs were aligned as rs2301756, rs12423190, rs12229892, rs7958372 and rs4767860. 
especially the rare SNPs, were associated with the lipid levels, as SNPs with low minor frequency had been reported to be associated with lipid profile [23-26]. Sequencing of the whole gene might be the solution. The another limitation was that the influence of life style on lipid levels could not be assessed because of the design, as previous studies had reported that lifestyle factors such as cigarette or alcohol consuming could affect lipid profile $[27,28]$. More rigorous design would be performed in the future study.

\section{Conclusions}

In summary, we found that SNPs of PTPN11 gene were associated with serum lipid levels in a sex-specific pattern. Rs12229892 and rs4767860 may play an important role in lipid profile in males, and rs2301756 and rs7958372 may be related to TG and LDL-C levels in females. Further studies are needed to explore the mechanism on how PTPN11 SNPs exert their effects on lipid profile.

\section{Abbreviations \\ SNPs: Single nucleotide polymorphisms; PTPN11: Protein tyrosine phosphatase, non-receptor 11; TG: Triglyceride; TC: Total cholesterol; HDL- C: High-density lipoprotein cholesterol; LDL-C: Low-density lipoprotein cholesterol; SHP2: Src homology-2 domain-containing protein tyrosine phosphatase 2; BMI: Body mass index; htSNPs: Haplotype tagging SNPs; MAF: Minor allele frequency; PCR: Polymerase chain reaction.}

\section{Competing interests}

The authors declare that they have no competing interests.

\section{Authors' contributions}

$J J$ and XYC designed the study. ZFJ, XYC, DHC and FK performed the experiments. ZFJ and $\mathrm{JJ}$ analyzed the data and wrote the first draft of manuscript. JJ and PK revised the manuscript. All authors read and approved the final manuscript.

\section{Acknowledgements}

This study was supported by the National Natural Science Foundation of China (Grant No. 81072369 and 30940060) and the Natural Science Fund of Jilin Province (Grant No: 201215035). The authors would like to thank all of those who participating in this study, especially to Chang-Song Guo for his work on sample collection.

\section{Author details}

'Division of Clinical Epidemiology, First Hospital of Jilin University, Changchun 130021, China. ${ }^{2}$ Department of Gastrointestinal Surgery, First Hospital of Jilin University, Changchun 130021, China.

Received: 15 March 2013 Accepted: 10 May 2013

Published: 14 May 2013

\section{References}

1. Castelli WP, Anderson K, Wilson PW, Levy D: Lipids and risk of coronary heart disease. The Framingham Study. Ann Epidemiol 1992, 2:23-28.

2. Kannel WB, Gordon T, Dawber TR: Role of lipids in the development of brain infarction: the Framingham study. Stroke 1974, 5:679-685.

3. Boden WE: High-density lipoprotein cholesterol as an independent risk factor in cardiovascular disease: assessing the data from Framingham to the Veterans Affairs High-Density Lipoprotein Intervention Trial. Am J Cardiol 2000, 86:19L-22L.

4. Gu D, Reynolds K, Wu X, Chen J, Duan X, Reynolds RF, Whelton PK, He J: Prevalence of the metabolic syndrome and overweight among adults in China. Lancet 2005, 365:1398-1405.
5. Thomsen SB, Rathcke CN, Skaaby T, Linneberg A, Vestergaard $\mathrm{H}$ : The association between genetic variations of $\mathrm{CHI} 3 \mathrm{~L} 1$, levels of the encoded glycoprotein YKL-40 and the lipid profile in a danish population. PLOS One 2012, 7:e47094.

6. Yin RX, Wu DF, Miao L, Aung LH, Cao XL, Yan TT, Long XJ, Liu WY, Zhang L, Li M: Several genetic polymorphisms interact with overweight/obesity to influence serum lipid levels. Cardiovasc Diabetol 2012, 11:123.

7. Lauriol J, Kontaridis MI: PTPN11-associated mutations in the heart: has LEOPARD changed its RASpots? Trends Cardiovasc Med 2011, 21:97-104

8. Krajewska M, Banares S, Zhang EE, Huang X, Scadeng M, Jhala US, Feng GS, Krajewski S: Development of diabesity in mice with neuronal deletion of Shp2 tyrosine phosphatase. Am J Pathol 2008, 172:1312-1324.

9. Ugi S, Maegawa H, Kashiwagi A, Adachi M, Olefsky JM, Kikkawa R: Expression of dominant negative mutant SHPTP2 attenuates phosphatidylinositol 3'-kinase activity via modulation of phosphorylation of insulin receptor substrate-1. J Biol Chem 1996, 271:12595-12602.

10. Phung $T L$, Roncone A, Jensen KL, Sparks CE, Sparks JD: Phosphoinositide 3-kinase activity is necessary for insulin-dependent inhibition of apolipoprotein B secretion by rat hepatocytes and localizes to the endoplasmic reticulum. J Biol Chem 1997, 272:30693-30702.

11. Cooke M, Orlando U, Maloberti P, Podestá EJ, Maciel FC: Tyrosine phosphatase SHP2 regulates the expression of acyl-CoA synthetase ACSL4. J Lipid Res 2011, 52:1936-1948.

12. Cooke M, Mele P, Maloberti P, Duarte A, Poderoso C, Orlando U, Paz C, Cornejo Maciel F, Podesta EJ: Tyrosine phosphatases as key regulators of StAR induction and cholesterol transport: SHP2 as a potential tyrosine phosphatase involved in steroid synthesis. Mol Cell Endocrinol 2011, 336:63-69.

13. Jamshidi Y, Gooljar SB, Snieder H, Wang X, Ge D, Swaminathan R, Spector TD, O'Dell SD: SHP-2 and PI3-kinase genes PTPN11 and PIK3R1 may influence serum apoB and LDL cholesterol levels in normal women. Atherosclerosis 2007, 194:e26-e33.

14. De La Vega FM: Selecting single-nucleotide polymorphisms for association studies with SNPbrowser software. Meth Mol Biol 2007 376:177-193.

15. Jiang J, Jia ZF, Kong F, Jin MS, Wang YP, Tian S, Suo J, Cao X: Association of polymorphism of PTPN 11 encoding SHP-2 with gastric atrophy but not gastric cancer in helicobacter pylori seropositive Chinese population. BMC Gastroenterol 2012, 12:89.

16. Lin DY, Zeng D, Millikan R: Maximum likelihood estimation of haplotype effects and haplotype-environment interactions in association studies. Genet Epidemiol 2005, 29:299-312

17. Kolovou V, Marvaki A, Karakosta A, Vasilopoulos G, Kalogiani A, Mavrogeni S, Degiannis D, Marvaki C, Kolovou G: Association of gender, ABCA1 gene polymorphisms and lipid profile in Greek young nurses. Lipids Health Dis 2012, 11:62.

18. Bermudez OI, Velez-Carrasco W, Schaefer EJ, Tucker KL: Dietary and plasma lipid, lipoprotein, and apolipoprotein profiles among elderly hispanics and non-hispanics and their association with diabetes. Am J Clin Nutr 2002, 76:1214-1221.

19. Okada R, Suzuki K, Nishio K, Ishida Y, Kawai S, Goto Y, Naito M, Wakai K, Ito $Y$, Hamajima N: Modification of the effect of smoking on cholesterol in Japanese carriers of a PTPN11 polymorphism. Mol Med Report 2008, 1:595-598.

20. Zhu F, Loh M, Hill J, Lee S, Koh KX, Lai KW, Salto-Tellez M, lacopetta B, Yeoh $K G$, Soong R: Genetic factors associated with intestinal metaplasia in a high risk Singapore-Chinese population: a cohort study. BMC Gastroenterol 2009, 9:76.

21. Hishida A, Matsuo K, Goto Y, Naito M, Wakai K, Tajima K, Hamajima N: Associations of a PTPN11 G/A polymorphism at intron 3 with helicobactor pylori seropositivity, gastric atrophy and gastric cancer in Japanese. BMC Gastroenterol 2009, 9:51.

22. Lu Y, Dolle ME, Imholz S, Van't Slot R, Verschuren WM, Wijmenga C, Feskens EJ, Boer JM: Multiple genetic variants along candidate pathways influence plasma high-density lipoprotein cholesterol concentrations. J Lipid Res 2008, 49:2582-2589.

23. Cohen JC, Kiss RS, Pertsemlidis A, Marcel YL, McPherson R, Hobbs HH: Multiple rare alleles contribute to low plasma levels of HDL cholesterol. Science 2004, 305:869-872

24. Polisecki E, Peter I, Robertson M, McMahon AD, Ford I, Packard C, Shepherd J, Jukema JW, Blauw GJ, Westendorp RG, et al: Genetic variation at the 
PCSK9 locus moderately lowers low-density lipoprotein cholesterol levels, but does not significantly lower vascular disease risk in an elderly population. Atherosclerosis 2008, 200:95-101.

25. Cohen JC, Boerwinkle E, Mosley TH Jr, Hobbs HH: Sequence variations in PCSK9, low LDL, and protection against coronary heart disease. N Engl J Med 2006, 354:1264-1272.

26. Hubacek JA, Wang WW, Skodova Z, Adamkova V, Vrablik M, Horinek A, Stulc T, Ceska R, Talmud PJ: APOA5 Ala315 > Val, identified in patients with severe hypertriglyceridemia, is a common mutation with no major effects on plasma lipid levels. Clin Chem Lab Med 2008, 46:773-777.

27. Cai H, Huang J, Xu G, Yang Z, Liu M, Mi Y, Liu W, Wang H, Qian D: Prevalence and determinants of metabolic syndrome among women in Chinese rural areas. PLoS One 2012, 7:e36936.

28. Li Q, Wei XL, Yin RX: Association of ATP binding cassette transporter G8 rs4148217 SNP and serum lipid levels in Mulao and Han nationalities. Lipids Health Dis 2012, 11:46.

doi:10.1186/1476-511X-12-72

Cite this article as: Jia et al:: Polymorphisms of PTPN11 gene could

influence serum lipid levels in a sex-specific pattern. Lipids in Health and Disease 2013 12:72

\section{Submit your next manuscript to BioMed Central and take full advantage of:}

- Convenient online submission

- Thorough peer review

- No space constraints or color figure charges

- Immediate publication on acceptance

- Inclusion in PubMed, CAS, Scopus and Google Scholar

- Research which is freely available for redistribution 